\title{
Os verbos fortes portugueses e a sua mudança vocálica*
}

Viviane Cunha***

RESUMO: Ressaltando a importância da vogal tônica e sua vulnerabilidade, analisa-se o processo da metafonia na $1^{\mathrm{a}}$ pessoa do singular do pretérito perfeito dos verbos fortes, e a atuação da analogia na regularização do sistemá de conjugação.

A vogal tônica é uma das entidades lingüísticas mais típicas e surpreendentes no âmbito da Fonologia. Dois traços a caracterizam: estabilidade, no sentido de que não está sujeita a fenômenos de síncope, apócope ou aférese (a não ser em raras exceções), e por outro lado, vulnerabilidade, pelo fato de ser a que mais sofre mudanças nas línguas. Veja-se, por exemplo, a ditongação românica, a qual tem causas diversificadas e, até mesmo, resultados diferentes em cada língua, mas em que a vogal atingida é sempre a tônica.

No caso do português, a vogal tônica tem um papel importantíssimo, pois, ao que tudo indica, está fortemente ligada à tipologia da língua. Há línguas em que ocorre uma distribuição harmoniosa das sílabas, com ligeira ênfase para distinguir a tônica, como o italiano e o espanhol, por exemplo. Já no português, há uma tendência a enfatizar demais a sílaba tônica, o que torna as pretônicas um pouco obscuras, e as postônicas quase desaparecidas, em face de sua débil atuação. Isto é mais evidente ainda nos falares de Portugal. O fato de a sílaba

\footnotetext{
* Recebido para publicação em agosto de 1996.

*** Professora Assistente de Filologia Românica do Departamento de Letras Românicas da Faculdade de Letias da UFMG.
} 
tônica ser mais enfática no português faz com que a vogal tônica portuguesa se torne mais evidente também.

É provável que a tendência à metafonia, tão expressiva no português, esteja proporcionalmente relacionada com o enfraquecimento das vogais átonas finais e das consoantes finais. Com a lenição desses fonemas, que são também, na maioria das vezes, morfemas, para que se faça a distinção entre singular e plural (caso do /s/), e masculino e feminino (caso do /a/ e do / $/$, grafado o), torna-se necessária esta espécie de flexão interna, que é a alternância da qualidade da vogal tônica, para marcar aquelas categorias gramaticais de número e de gênero. Mas não são apenas os nomes que são atingidos por flexões internas, no português. O sistema verbal também está marcado por alternâncias vocálicas, não somente provenientes de resultados metafônicos, como também, algumas vezes, resultantes de apofonia.

A questão da tonicidade tem a ver, é claro, com o ritmo da língua. Segundo Entwistle, ${ }^{i}$ o português é uma língua de ritmo trocaico, assim como o espanhol e o catalão, isto é, no seu repertório léxico predominam os vocábulos paroxítonos. A ilustre professora Ângela Vaz Leão, num trabalho inédito, observa que as palavras proparoxítonas portuguesas são em geral empréstimos latinos, enquanto as oxítonas ou são palavras provenientes de paroxítonas no latim, que tiveram apócope de $\underline{\mathbf{e}}$ final em português (como o infinitivo dos verbos) ou que sofreram síncope seguida de crase (como germana- $>$ irmãa $>$ irmã), ou são empréstimos exóticos (bambu, angu, etc), ou, ainda, são hipocorísticos (papai, Zezé, etc). As palavras hereditárias e as de formação vernácula que correspondem à maioria do léxico português (salvo as exceções acima), são palavras predominantemente paroxítonas.

Assim sendo, é comum na língua portuguesa a vogal tônica fazer parte do radical de uma palavra, embora, nos derivados, possa também aparecer no sufixo. Tal fato possibilita uma série de alternâncias vocálicas nas raízes dos verbos portugueses. Estes apresentam um tipo de metafonia bastante específi$\mathrm{ca}$, em relação às demais classes de palavras. Nos verbos, em geral, ela ocorre não somente por causa das vogais átonas finais /a/ e /u/, mas também,-por contacto com semivogal, e ainda por influência de /i/ final, no caso dos pretéritos fortes.

O sistema verbal português é dos mais complexos, pois, além do conjunto de sufixos modo-temporais e sufixos número-pessoais usados para expres-

1 ENTWISTLE, William J. The Spanish Language Together with Portuguese, Catalan and Basque. Trad. esp.: Las lenguas de España: castellano, catalán, vasco y gallego-portugués. Madrid, Istmo, 1982. p.77. 
sar modos, tempos e pessoas, lança mão, também, da alternância vocálica, na distinção de pessoas, como em fiz, fez; fui, foi; distingue ainda formas verbais como pode (pretérito perfeito) e pọde (presente do indicativo).

Devido a essa complexidade, que por si só seria assunto para inúmeros trabalhos, tratarei aqui apenas daqueles casos evidentes de metafonia, no pretérito perfeito do indicativo de alguns verbos fortes.

Dos verbos de pretérito perfeito forte em português, interessa-nos, no presente estudo, o quadro sincrônico, já que, entre o latim vulgar e o português arcaico e entre este e o português moderno, houve muitos verbos fortes que desapareceram ou que se tornaram fracos, na fase arcaica ou no limiar da moderna. Como este trabalho pretende apenas uma abordagem da metafonia, tomarei, como exemplos para estudo, somente as formas que apresentam alternância vocálica nos radicais e são, no consenso geral, resultantes de metafonia.

O quadro sincrônico dos verbos portugueses que apresentam alternância vocálica entre a $1^{\mathrm{a}}$ e a $3^{\mathrm{a}}$ pessoas do singular do pretérito perfeito do indicativo é o seguinte:

\section{QUADRO 1}

\begin{tabular}{|c|c|c|}
\hline Infinitivo & $\begin{array}{l}1^{\mathrm{a}} \text { p. s. pret. } \\
\text { perf. ind. }\end{array}$ & $\begin{array}{l}3^{\mathrm{a}} \text { p. s. pret. perf. } \\
\text { ind. }\end{array}$ \\
\hline - estar & estive & estęve \\
\hline fazer & fiz & feg $z$ \\
\hline - ir & fui & foi \\
\hline poder & pude & pode \\
\hline por & pus & pos \\
\hline - ser & fui & foi $\mathrm{i}$ \\
\hline ter & tive & teve \\
\hline vir & vim & vẹio \\
\hline
\end{tabular}

Deixarei de lado, pelo menos por enquanto, os verbos estar, ir e ser, cujas alternâncias vocálicas na $1^{\mathrm{a}}$ e $3^{\mathrm{a}}$ pessoas do singular do pretérito perfeito não se explicam pela metafonia.

Entre as formas de que me ocuparei, algumas, isto é, as de $1^{a}$ pessoa são resultantes de metafonia. É o caso por exemplo, de fiz $<$ fẻci, pude $<$ pŏtui, pus $<$ pŏsui, tive < tēnui, vim < vēni, onde o /i/ final influenciou a vogal tônica, tendo esta se transformado de média em alta. Em outras palavras houve uma assimilação à distância cujo resultado foi o alçamento da vogal tônica. Observe-se que se trata de assimilação total em 
fëci $>$ fezi $>$ fizi $>$ fize $>$ fiz,

tënui $>$ teui $>$ tevi $>$ tivi $>$ tive,

vēni $>$ vini $>$ vĩi $>$ vĩ/vim,

porque as duas vogais, isto é, a assimiladora e a assimilada, pertencem à mesma série (anterior). Já nas formas verbais

pŏsui $>$ posi $>$ pusi $>$ puse $>$ pus,

pŏtui $>$ podui $>$ podi $>$ pudi $>$ pude,

a assimilação é parcial, porquanto as duas vogais, ativa e passiva, do processo de assimilação, pertencem a séries diferentes (anterior e posterior).

Para pude e pus, alguns autores costumam dar como étimo as formas hipotéticas do latim vulgar "poti e *posi respectivamente. Essa questão deixa de ser relevante, já que em ambos os étimos há presença do /i/. Partindo-se de pŏtui e pŏsui, teríamos que considerar duas fases da metafonia: a primeira, provocada por metátese de $\mathbf{u}$ (provavelmente semivogal $/ \mathrm{w} /$ ) e à segunda, por influência de /i/ átono final:

$$
\begin{aligned}
& \text { pŏsui }>\text { "pousi }>\text { puse }>\text { pus } \\
& \text { pŏtui }>\text { "podui }>\text { "poudi }>\text { pudi }>\text { pude. }
\end{aligned}
$$

É interessante observar ainda que, nas formas de $3^{\mathrm{a}}$ pessoa de singular pode < pŏtuit e pos < pŏsuit, houve um fechamento de um grau do timbre da vogal tônica, que passou de $/ \mathrm{s} / \mathrm{para} / \mathrm{o} /$. Depois que o /t/ final sofreu apócope, fenômeno muito antigo, que talvez remonte ao latim, o /i/ das formas de $3^{\mathrm{a}}$ pessoa ficou sendo final, e assim, pode ser que tenha feito fechar o timbre da vogal média em pǒde < potŭ(t) e pos < posŭ(t). Por outro lado, nas outras pessoas não houve /i/ final e, entretanto, tiveram, no português arcaico, a vogal média da raiz com o mesmo timbre fechado (cf. quadro 2).

A grande questão que se coloca em relação ao pretérito perfeito dos verbos fortes é a da manutenção das vogais altas (anterior e posterior) no radical das outras pessoas, já que no português arcaico elas conservavam a vogal latina, como se pode verificar no quadro abaixo: 


\section{QUADRO 2}

\begin{tabular}{|c|c|c|}
\hline $\begin{array}{l}\text { Latim } \\
\text { fẽci }\end{array}$ & $\begin{array}{l}\text { Port. arcaico } \\
\text { fize }>\text { fiz (metaf.) }\end{array}$ & $\begin{array}{l}\text { Portmodemo } \\
\text { fiz }\end{array}$ \\
\hline fecisti & fezeste & fizeste \\
\hline fecĭt & feze $>$ fezz & $\mathrm{fez}$ \\
\hline fecĭmus & fezemos & fizemos \\
\hline fecisstis & fezestes & fizestes \\
\hline fecērunt & fezerom & fizeram \\
\hline pŏsui & puse (puge) $>$ pus (metaf.) & pus \\
\hline posuisti & poseste & puseste \\
\hline postŭt & pôs & pôs \\
\hline posuimus & posemos & pusemos \\
\hline posuistis & posestes & pusestes \\
\hline posuērunt & poserom & puseram \\
\hline pōtui & pude (metaf.) & pude \\
\hline potuisti & podeste & pudeste \\
\hline potul̆t & pôde & pôde \\
\hline potuimus & podemos & pudemos \\
\hline potuistes & podestes & pudestes \\
\hline potuērunt & poderom & puderam \\
\hline tēnui & tiue/tive (metaf.) & tive \\
\hline tenuisti & teueste/teveste & tiveste \\
\hline tenul̆t & teue/teve & teve \\
\hline tenuimus & teuemos/tevemos & tivemos \\
\hline tenuistis & teuestes/tevestes & tivestes \\
\hline tenuērunt & teuerom/teverom & tiveram \\
\hline vēni & vii (metaf.) & vim \\
\hline venisti & vẽeste & vieste \\
\hline venit & vẽ̃i & vei $+u>$ veio \\
\hline venŭmus & vẽimos & viemos \\
\hline venistis & vẽestes & viestes \\
\hline venērunt & vẽerom & vieram \\
\hline
\end{tabular}


No quadro 2 , podemos observar que a forma metafonizada da $1^{\mathrm{a}}$ pessoa do singular dos verbos arrolados ${ }^{2}$ era distinta da forma de $3^{\mathrm{a}}$ pessoa do singular, na época arcaica. No português moderno, para se evitar uma homonímia entre a $1^{\mathrm{a}}$ e $3^{\mathrm{a}}$ pessoas do singular, conservou-se a forma arcaica de $3^{\mathrm{a}}$ pessoa.

Quanto às outras pessoas, a presença de $/ \mathrm{i} /$ ou $/ \mathrm{u} /$ no radical, parece ter sido determinada pela analogia com a $1^{\mathrm{a}}$ pessoa. Mas isso não é ponto pacífico entre os autores. Se alguns, como, por exemplo, Nunes, ${ }^{3}$ postulam que as formas modernas com /i/ ou $/ \mathrm{u} /$ no radical foram influenciadas pela $1^{\mathrm{a}}$ pessoa (forma metafonizada), já outros, como $\mathrm{Meier}^{4}$ não admitem que uma só pessoa possa influenciar todas as outras. Como se vê, a questão é polêmica, e tentar esclarecê-la, apesar de ser um desafio interessante, ultrapassa os objetivos deste trabalho. Pode-se lembrar, entretanto, que na analogia não é relevante o número de formas ativas, mas, sim, a precedência da forma ativa no paradigma (ou nas relações paradigmáticas). Lembre-se, por exemplo, a série dos pronomes possessivos portugueses, meu, teu, seu, onde as formas de $2^{\mathrm{a}}$ e $3^{\mathrm{a}}$ pessoas se regularizaram pela $1^{\mathrm{a}}$ (forma prioritária no paradigma). No latim, como se sabe, as formas das três pessoas do singular dos possessivos eram $\mathbf{m e u}(\mathbf{m}), \operatorname{tuu}(\mathbf{m}), \operatorname{suu}(\mathbf{m})$, tendo, apenas a forma da $1^{\mathrm{a}}$ pessoa passado ao português. Sequeira ${ }^{5}$ afirma que

(...) a analogia, ao unificar flexões paralelas que estavam diferenciadas, procede sobretudo por generalização, visto que intervém para modelar fenômenos particulares por fenômenos de maior extensão. Tende ela assim (...) a restaurar a simetria perdida nos sistemas flexionais. Todavia, o sentido, a direção da força analógica, o seu alcance mesmo, variam com a época e com as circunstâncias peculiares do termo visado e ainda conforme o eixo de simetria tomado para fulcro da unificação: pessoa, modo ou tempo.

As formas do pretérito perfeito dos verbos fortes estar, ir e ser também se explicam pela analogia. A $1^{\text {a }}$ pessoa latina steti foi pouco a pouco abandonada em favor de estive, provavelmente por analogia com as formas dos verbos ter ou ser: tive e sive (arc.), tendo as outras pessoas o mesmo destino. $\mathrm{O}$

2 É sabido que o pretérito perfeito arcaico dos verbos fortes apresenta grande número de variantes sobretudo na $3^{\mathrm{a}} \mathrm{p}$. sing. Das várias formas documentadas considerei apenas aquela que viria a predominar ao longo da evolução da língua e que é precisamente a que interessa ao meu estudo.

3 NUNES, J. J. Compêndio de gramática história portuguesa. Lisboa, Livraria Clássica, 1975. p.310-311.

4 MEIER, Harri. Ensaios de Filologia Românica. Rio de Janeiro, Grifo, 1974. págs. 54-60.

5 SEQUEIRA, F.J.M. Aspectos do português arcaico. Lisboa, Liviaria Popular, 1943. p. 164. 
pretérito perfeito do verbo ire latino também desapareceu, tendo-se adotado o modelo do perfeito de ser em português. O verbo ser, que teve as formas de $1^{\text {a }}$ e $3^{a}$ pessoas do singular iguais, na fase arcaica, buscou no paradigma latino fui a forma moderna de $1^{\text {a }}$ pessoa (fui) para desfazer a homonímia.

Finalmente, pode-se dizer que no pretérito perfeito dos verbos fortes portugueses a metafonia ocorreu na $I^{a}$ pessoa do singular por influência de /i/ átono final, passando as vogais médias (tanto anteriores como posteriores) a vogais altas: /i/ e /u/ respectivamente. Na fase moderna da língua as outras pessoas se regularizaram pela $1^{\mathrm{a}}$ pessoa (forma metafonizada). Apenas a $3^{\mathrm{a}}$ pessoa do singular conservou a vogal tônica arcaica para que se mantivesse a diferenciação entre ela e a $1^{\mathrm{a}}$, evitando assim a homonímia.

RESUMEN: Acentuando la importancia de la vocal tónica y su vulnerabilidad, se analiza el proceso de inflexión en la primera persona del singular del pretérito perfecto simple de los verbos fuertes y la actuación de la analogía en la regularización del sistema de conjugación. 